\title{
Medium Frequency Electric Field Analysis of Power Transformers in High Voltage System
}

\author{
Yıldırım ÖZÜPAK \\ Dicle University, Silvan Vocational School, Electrical and Energy Department, Diyarbakır, TURKEY
}

\section{Keywords}

Electric field,

FEM,

Medium frequency,

Magnetic flux.

\begin{abstract}
Electronic power transformers (EPT) are transformers that are smaller in size and volume compared to conventional $50 \mathrm{~Hz}$ frequency transformers. Medium frequency transformers (MFT) have begun to become important components in high voltage and high power energy conversion systems such as EPTs. In this study, the electric field distribution of these transformers is discussed. The electric field distributions in the transformer have been obtained using the two-dimensional finite element method (FEM). Besides, maximum electric field intensities were obtained in the study. ANSYS@Maxwell simulation program, which realizes a solution based on FEM, was used for these analyzes. Electromagnetic field analyzes of the same transformer under normal conditions were also performed to compare the analyzes. Besides, the values obtained from the high-frequency analysis, the values obtained from the study below $50 \mathrm{~Hz}$ frequency, and the values obtained experimentally were compared. In this way, the stress in the insulation material of the transformer and the weak parts of the insulation material were detected. It is expected that the method used will contribute to future studies to examine the results of the electric field distribution analysis of transformers.
\end{abstract}

\section{Introduction}

Medium frequency transformers (MFT) are expected to play an important role in current electricity transmission and distribution systems and in the future smart grid system. A lot of work has been done on these transformers in recent years. Previous studies on this subject are available in the literature. A thermal model developed with a multi-layer winding consisting of the theoretical calculation of the maximum electric field strength has been developed [1]. A medium frequency power transformer design has been proposed to reduce the transformer's leakage inductance, core and winding losses, thermal management, and high insulation requirements [2]. Two different transformer concepts, which are aimed at different power levels and high efficiency, improved in terms of the core material and cooling methods, have been created and researches have been made on the effectiveness of the insulation methods used in the long term [3]. In order to analyze the voltage stress occurring in the time and frequency domains in the step converters, different operating conditions have been considered [4]. The highest electric field was seen in the MFT of the dc-dc converters of the converter cells. The durable insulation material is very important for transformers used in high voltage power systems. Because high voltage causes the partial discharge of transformers, deterioration of insulation, and failure of transformers [5].

Until it reaches the normal current value, it gradually decreases with the effect of oscillation damping caused by the impedance of the system to which it is connected, as well as the winding and magnetization resistance of the transformer [6]. The excitation properties of the transformer core are expressed by the nonlinear relationship between flux and magnetizing current. Steady-state transformers are designed to operate below their saturation curves. However, when the transformers are energized, the flux rises to a high value in the saturation region with the effect of inrush current, such that the magnetizing current increases substantially [7-9]. Inrush current in transformers is considered a major problem in practical power systems. Due to its high current, it may cause effects such as insulation failure, mechanical stress in transformer windings, and power quality problems [10]. It can also affect sensitive protection devices [11]. Different ways to calculate and reduce these inrush currents have been studied and analyzed in the literature.

In this paper, the effect of MFT on electric field distribution was investigated. The electric field distributions of the transformer windings were examined using the 2-D finite element method (FEM) and the analysis on this subject was carried out. To examine the effect of high frequency on the transformer, $50 \mathrm{~Hz}$ frequency analyzes of the transformer under normal conditions were also performed and the results were compared.

\section{Material and method}

\subsection{Mathematical Basics of Electric Field}

With The physical basis for electric field problems can be derived by expressing Poisson's equation, which describes the variation of the field as a general quadratic partial differential equation with associated boundary conditions.

In the electrostatic field, the field density is given by:

$$
E=-\nabla \emptyset
$$

Where is the potential and $\nabla$ is the gradient operator. Assuming that $\mathrm{i}$ and $\mathrm{j}$ represent unit vectors directed along the $\mathrm{x}$ and $\mathrm{y}$ axes, respectively, the gradient operator can be expressed as:

$$
\nabla=\frac{\partial}{\partial x} i+\frac{\partial}{\partial y} j
$$

Flux density in a linear medium:

$$
D=\varepsilon E
$$

expressed in the form. If the equation is written instead of 1 :

$$
D=-\varepsilon \nabla \emptyset
$$

*Corresponding Author: yildirim.ozupak@dicle.edu.tr

(Y. Özüpak Orcid: 0000-0001-8461-8702)
Received 31 Jan 2021 Revised 08 Feb 2021 Accepted 08 Feb 2021 2687-5195 @ 2019 ACA Publishing. All rights reserved. 
where $\varepsilon=\varepsilon_{0} \cdot \varepsilon_{\mathrm{r}}$ and $\varepsilon_{0}, \varepsilon_{\mathrm{r}}$ are the permeability of the vacuum and the relative permeability of the medium, respectively. On the other hand, according to the law of conservation of flux, the flux leaving a differential volume is equal to the same volume of charge.

$$
\nabla D=f
$$

If equation 4 is replaced in 5, the new formula will be like equality 6

$$
-\nabla(-\varepsilon \nabla \emptyset)=f
$$

If the environment is homogeneous;

$$
-\varepsilon \nabla^{2} \emptyset=f
$$

Equation 7 is the Poisson equation for a linear homogeneous medium If $\mathrm{f}=0$, that is, there is no internal charge, Equation 7 :

$$
-\varepsilon \nabla^{2} \emptyset=0
$$

Laplace equation becomes for a linear homogeneous medium. For an anisotropic medium where is a function of position and direction.

$$
\varepsilon=\left[\begin{array}{ll}
a_{11} & a_{12} \\
a_{21} & a_{22}
\end{array}\right]
$$

Where $a_{11}, a_{12}, a_{21}$ and $a_{22}$ are the position and reference function of the local angle between the principal axis. If the environment is isotropic, $a_{11}=a_{22}=\varepsilon$ and $a_{12}=a_{21}=0$. Equation is obtained by making it into the general form of the Poisson equation if 8 equations are replaced in 6 .

$$
\frac{\partial}{\partial x}\left(a_{11} \frac{\partial \emptyset}{\partial x}+a_{12} \frac{\partial \emptyset}{\partial y}\right)-\frac{\partial}{\partial y}\left(a_{21} \frac{\partial \emptyset}{\partial x}+a_{22} \frac{\partial \emptyset}{\partial y}\right)=f
$$

\subsection{Electric Field Analysis Using Finite Element Method}

Electric field analysis calculates the electric field in conductive or capacitive systems. Typical quantities of interest in an electric field analysis include:

-Electric field

-Current density

-Load density

-Transmission Joule heat.

Electric field analysis plays an important role in the design of many engineering applications: busbars, fuses, transmission lines, etc. ANSYS uses the Poisson equation for static electric field analysis. The primary unknowns (degrees of freedom) calculated by the finite element solution are the electrical scalar potential. Other quantities of the electric field are then derived from the node potential.

The first derived result is the electric field. It is defined as the negative gradient of the electric scalar potential. This evaluation is performed at integration points using element shape functions:

$$
\{E\}=-V\{N\}^{T}\left\{V_{e}\right\}
$$

where $\{\mathrm{E}\}$ is the electric field, $\mathrm{V}$ is the gradient operator, $\{\mathrm{N}\}$ is the shape functions, $\{$ And $\}$ is the node electric scalar potential.

The electric flux density is calculated from the electric field equation as follows:

$$
\{D\}=[\varepsilon]\{E\}
$$

Here $\{D\}$ is the electric flux density, $[\varepsilon]$ is the permeability matrix.

The nodal values of field density and flux density are calculated from the integration point values. The electric field analysis procedure using computer MFT ware (ANSYS) consists of three main steps; First, the model is drawn using ANSYS commands consisting of exact dimensions in MKS, and the model has meshed with sufficient density. Then, the solution is obtained by applying the loads to the boundary of the model. Finally, the results are taken as figures, graphics, or tables. The analysis is performed using a twodimensional model.

In this study, the electric field distribution of MFT is realized as 2-D with the simulation and analysis program ANSYS@Maxwell, which realizes a solution based on the finite element method. The maximum operating voltage of the EGT used is $11 \mathrm{kV}$. The safety factor should be taken into account when determining the insulation distance. The converter used for high-frequency analysis is given in Figure 1. This converter for each phase has been defined separately in the program environment. The shape of the MFT is presented in Figure 2. The mesh structure of the transformer is given in Figure 3. The core material is $0.27 \mathrm{~mm}$ thick silicon steel. B-H curve data of the magnetic core were taken from the program environment. Figure 4 shows the core B-H curve.

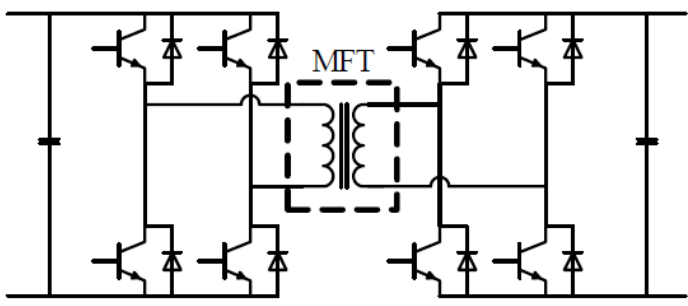

Figure 1. The converter used is given.

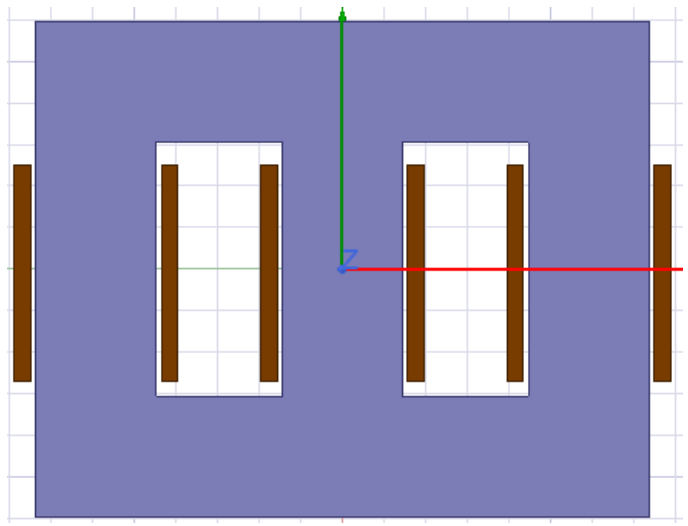

Figure 2.The structure of MFT

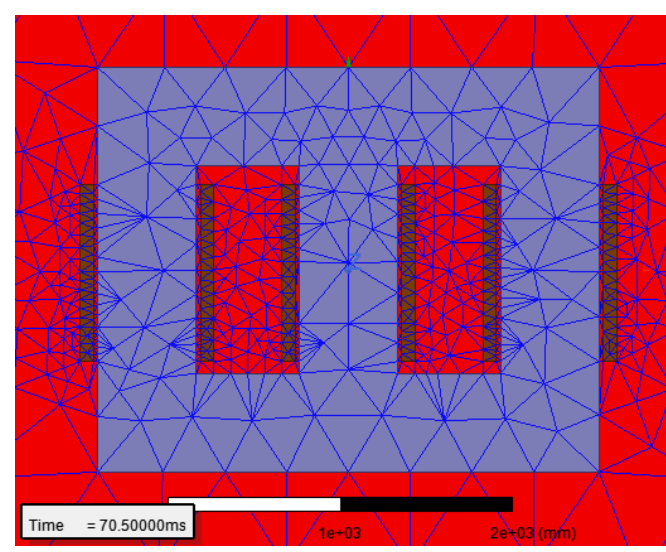

Figure 3. Finite element model of the transformer and braided winding design scheme 2-D model 


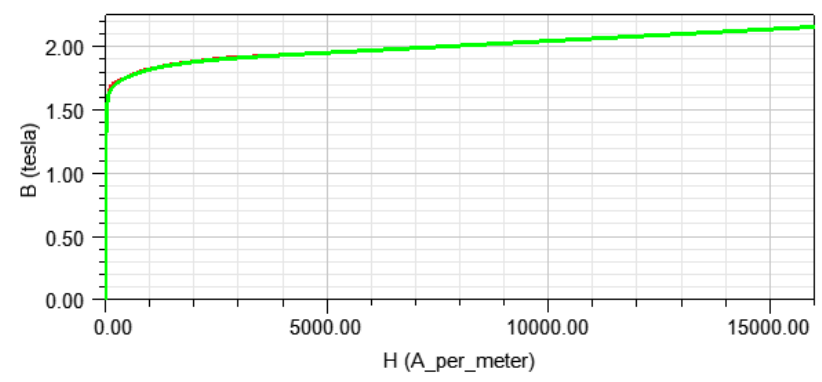

Figure 4. Core material B-H curve

The characteristics and parameters of the transformer used are presented in Table 1.

Table 1. Some properties of the modeled transformer used in simulation

\begin{tabular}{ll}
\hline Parameter & Value \\
\hline HV Winding Resistance & $1.7 \Omega$ \\
LV Winding Resistance & $40 \mathrm{~m} \Omega$ \\
HV phase current & $152 \mathrm{~A}$ \\
LV phase current & $785 \mathrm{~A}$ \\
Io & $\% 0.44$ \\
HV current density & $3.81 \mathrm{~A} / \mathrm{m}^{2}$ \\
LV current density & $3 \mathrm{~A} / \mathrm{m}^{2}$ \\
\hline
\end{tabular}

\section{Results and discussion}

In this paper, the electric field research of a transformer is explained and the results obtained are presented. The electric field study of the transformer consists of the field distribution around the windings and in the transformer oil. The analysis was carried out by subjecting the transformer to high and nominal short-term power frequency voltage. The magnitude of the electric field was obtained along a line from the outer corner of the core to the primary winding. The decrease or increase of the electric field along this line varies according to the starting or ending point of that line.

\subsection{Analysis of Transformer Under Normal Conditions}

In this section, electromagnetic field analysis, loss values, and electromagnetic forces in the windings of the transformer are obtained for the steady-state condition. An exponentially increasing voltage excitation given in the below equations was given to the program for analysis.

$$
\begin{array}{r}
V_{a}=V_{p}\left(1-e^{1-50 \cdot t}\right) \cdot \cos (2 \cdot \pi \cdot t \cdot 50) \\
V_{b}=V_{p}\left(1-e^{1-50 \cdot t}\right) \cdot \cos \left(2 \cdot \pi \cdot t \cdot 50+\frac{2}{3} \cdot \pi\right) \\
V_{c}=V_{p}\left(1-e^{1-50 \cdot t}\right) \cdot \cos \left(2 \cdot \pi \cdot t \cdot 50+\frac{4}{3} \cdot \pi\right)
\end{array}
$$

The magnetic flux distribution of the transformer modeled in ANSYS@Maxwell 3D environment is presented in Figure 5.

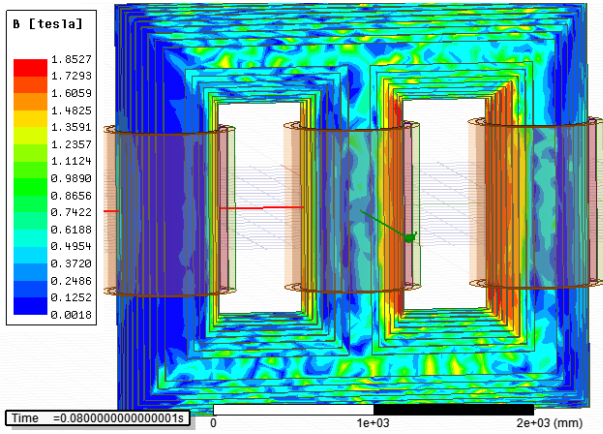

Figure 5. Magnetic flux distribution of the model

Magnetic field strength was also obtained from the analysis in the study. The magnetic field strength in the windings is presented in Figure 6. The strains in the windings can be seen from the field intensity distribution. Difficulties have occurred in the winding isolation especially in the third phase. Excessive stress may cause the insulation material to deteriorate or even perforate.

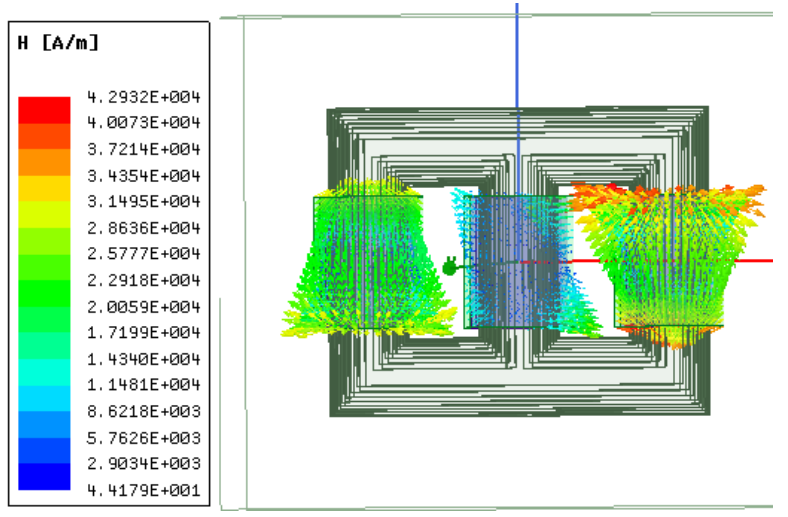

Figure 6. Magnetic field intensity in the windings

\subsection{Medium Frequency Electric Field Analysis of Transformer}

In this section, electric field analyzes of the transformer have been carried out. The electric field study of the modeled transformer consists of the internal connections around the windings and the field distribution in the transformer oil. The amplitude of the electric field is given in Figure 7

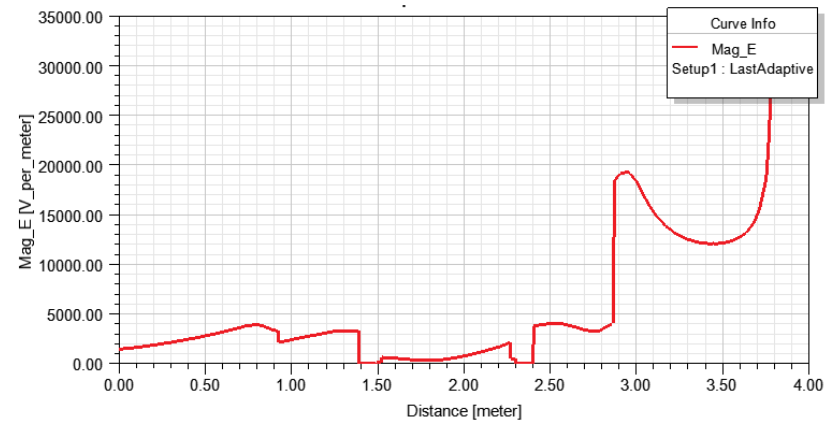

Figure 7. Electric field curve of the transformer

The two-dimensional analysis is sufficient to determine the maximum and minimum areal density points. For this purpose, horizontal and vertical section examinations of the transformer were made. When the applied high voltage is $1 \mathrm{MV}$, the outer layer of the HV winding is exposed to different field intensity levels far from the center of the applied voltage. However, the electric field intensity is 
greater at one point. The voltage distribution and electric field distribution on the transformer are presented in Figure 8-10.

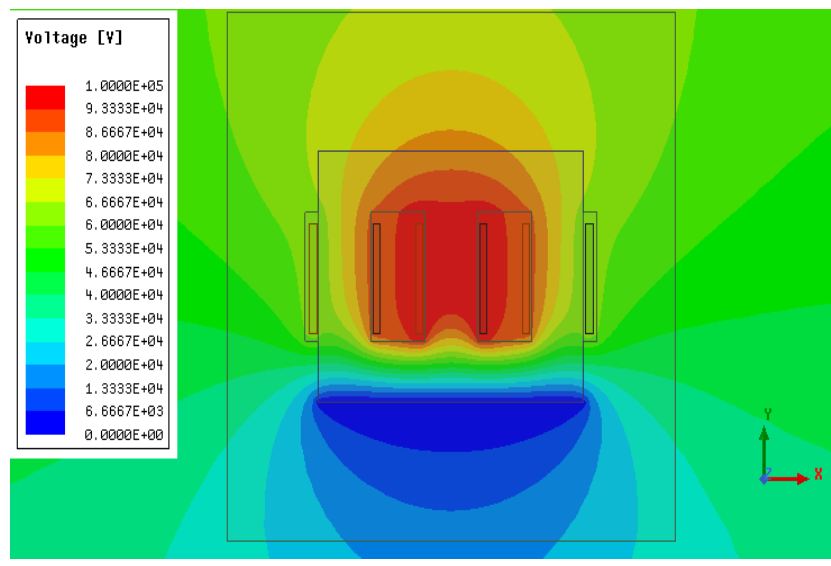

Figure 8. Stress and voltage distribution in 2D transformer model.

The electric field distribution at the top of the insulation material between the primary and secondary windings in the two-dimensional transformer model is given in Figure 9.

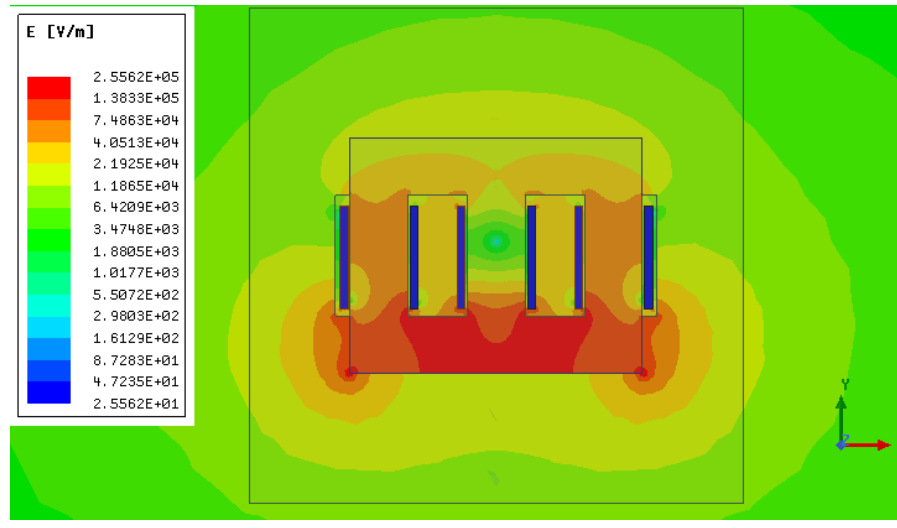

Figure 9. Electric field distribution in the model

The electric field intensity distribution in the two-dimensional transformer model is shown in Figure 10.

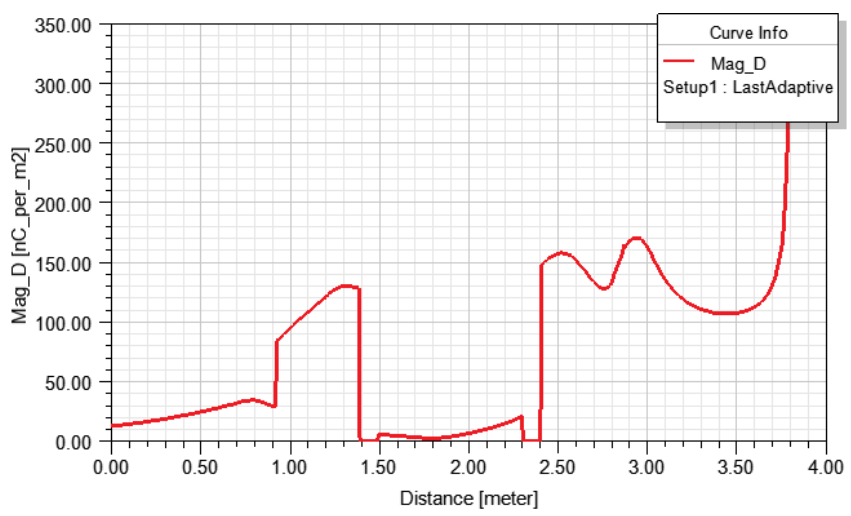

Figure 10. Electric field intensity in 2D transformer model.

\subsection{Comparison of Results}

Modeled transformer has been analyzed for two cases. It has been analyzed under both normal operating conditions and inrushes current and the results are compared. The results obtained are presented in Table 4.
Table 4. Comparison of results

\begin{tabular}{llll}
\hline & $\begin{array}{l}\text { Electric } \\
\text { field }\end{array}$ & $\begin{array}{l}\text { Magnetic } \\
\text { field } \\
\text { intensity }\end{array}$ & $\begin{array}{l}\text { Electromagnetic } \\
\text { force }\end{array}$ \\
\hline $\begin{array}{l}\text { Normal } \\
\text { condition }\end{array}$ & $\begin{array}{l}0.8510^{2} \\
\mathrm{~V} / \mathrm{m}\end{array}$ & $\begin{array}{l}\mathrm{H}=2861 \\
\mathrm{~A} / \mathrm{m}\end{array}$ & $1.402 \mathrm{~N}$ \\
\hline $\begin{array}{l}\text { Medium } \\
\text { frequency }\end{array}$ & $\begin{array}{l}2.5510^{5} \\
\mathrm{~V} / \mathrm{m}\end{array}$ & $\begin{array}{l}\mathrm{H}=8871 \\
\mathrm{~A} / \mathrm{m}\end{array}$ & $4326 \mathrm{~N}$ \\
& & &
\end{tabular}

Critical areas that can cause deterioration in the insulation materials between the windings have been identified. The electric field distribution in critical regions on the insulation material of the twodimensional model is also shown. As can be seen in the figures above, the peak value of the electric field intensity can occur at the corner of the conductors, at the middle edge of the conductors.

The voltage gradients have caused different electric field values in different regions. A significant voltage concentration zone is seen between the corner of the HV winding and the core edge. The electric field strength has reached its maximum value from this view. The maximum point is shown in red. The maximum zone has been formed to have the minimum distance from the HV outer layer to the earth's potential. Values of other electric field strengths are shown in $\mathrm{kV} / \mathrm{cm}$ in the yellow zone and green zone, respectively. The electric field concentration distribution can be seen in the top view of the model. From this point of view, the maximum field strength is seen as the red zone between the $\mathrm{HV}$ windings and the tank wall, which can be read directly.

\section{Conclusion}

In In this paper, the electric field analysis MFT ware package of a medium frequency transformer is analyzed using FEM-based ANSYSMaxwell. Dielectric stress gradients along the most probable failure paths for the dielectric field model in the insulating medium and especially design considerations were determined using the 2-D model in ANSYS environment. Testing the nominal short-duration high-frequency voltage of the transformer was taken into account in the study. Possible discharge points and electric field density distribution arising from voltage gradients were determined using the results of FEM analysis. The electric field distributions for the windings were examined using 2-D FEM and the results showed that the smaller maximum electric field density of the copper conductor can be obtained. It has also been observed that when the insulation distance is constant, the maximum electric field density can increase. Therefore, it is recommended to change the insulation distance if the intermittent winding is used.

\section{Declaration of Conflict of Interests}

The author declares that there is no conflict of interest. They have no known competing financial interests or personal relationships that could have appeared to influence the work reported in this paper.

\section{References}

[1.] Heatcote M, J\&P Transformer Book. Thirteenth Edition, Oxford, United Kingdom, Newness An imprint on Elsevier (2007).

[2.] Turan H, Çekirdekli D Hava Aralığı Bulunan Reaktör Çeşitlerinin Irdelenmesi ve Bir Prototip için Uygulama Örneği. Yüksek Lisans Tezi, Kocaeli Üniversitesi, Kocaeli, Türkiye, (2007). 
[3.] Dönük A, Modeling and Design of Iron-Core Shunt Reactors With Discretely Distributed Air-Gaps. Doktora Tezi, ODTÜ, Ankara, Turkey, (2012).

[4.] Zheng T, Zhao YJ, Ying J, Chen PL, Zhang FF "Design and analysis on the turn-to-turn fault protection scheme for the control winding of a magnetically controlled shunt reactor". IEEE Transactions, 30(2), (2015), 967-975.

[5.] Wojda R.P, Kazimierczuk, M.K "Analytical winding size optimization for different conductor shapes using Ampère's Law", Power Electronics, IET, 6 (6), (2013), 1058-1068.

[6.] Özüpak Y, MAMIS M. S Realization of electromagnetic flux and thermal analyses of transformers by finite element method. IEEJ Transactions on Electrical and Electronic Engineering, 14(10), (2019), 1478-1484. Doi: 10.1002/tee.22966.

[7.] Özüpak Y, MAMIS M. S, TEKE İ. H Electromagnetic Field and Total Loss Analysis of Transformers by Finite Element Method. International Journal of Engineering And Computer Science, 8(1) (2019), 24451-24460. (Yayın No: 5774086)

[8.] Yazdani-Asrami M, Mirzaie M, Akmal A. S No-load loss calculation of distribution transformers supplied by nonsinusoidal voltage using three-dimensional finite element analysis, Energy, vol. 50, no. 1, (2013), pp. 205-219.

[9.] M. Ostrenko and B. Andriienko, "Transformer impulse surges calculation by FEM coupled to the circuit," in IEEE Transactions on Magnetics, vol. 53, no. 6, pp. 1-4, June (2017), Art no. 7401804

[10.] T. Zupan, B. Trkulja, R. Obrist, T. Franz, B. Cranganu-Cretu, and J. Smajic. Transformer windings rlc parameters calculation and lightning impulse voltage distribution simulation. IEEE Transactions on Magnetics, 52(3):1-4, March (2016).

[11.] Wojda R.P, Kazimierczuk, M.K, Analytical winding size optimization for different conductor shapes using Ampère's Law", Power Electronics, IET, 6 (6), (2013),"1058-1068.

[12.] Yugendra Rao K N, Dynamic Modeling and Calculation of Self and Mutual Inductance between a Pair of Coils for Wireless Power Transfer Applications using ANSYS Maxwell, International Advanced Research Journal in Science, Engineering and Technology Vol. 2, Issue 10, (2015.
[13.] T. Zupan, B. Trkulja, R. Obrist, T. Franz, B. Cranganu-Cretu, and J. Smajic. 2016. "Transformer windings rlc parameters calculation and lightning impulse voltage distribution simulation", IEEE Transactions on Magnetics, vol.52, no.3, s.1-4, March.

[14.] M. Ostrenko and B. Andriienko, Transformer impulse surges calculation by FEM coupled to circuit," in IEEE Transactions on Magnetics, vol. 53, no. 6, pp. 1-4, (2017) June, Art no. 7401804

[15.] Zheng $\mathrm{T}$, Zhao YJ, Ying J, Chen PL, Zhang FF "Design and analysis on the turn-to-turn fault protection scheme for the control winding of a magnetically controlled shunt reactor". IEEE Transactions, 30(2), (2015). 967-975.

[16.] B. Qi, X. Zhao, C. Li, H. Wu, Transient electric field characteristics in oil-pressboard composite insulation under voltage polarity reversal. IEEE Trans. Dielectr. Electr. Insul., 22, (2015). 2148-2155.

[17.] P. Huang, C. Mao, D. Wang, Electric Field Simulations and Analysis for High Voltage High Power Medium Frequency Transformer" Energies, vol.10, no.3, s.371, doi:10.3390/en10030371. (2017).

[18.] M. Ostrenko, B. Andriienko, Transformer impulse surges calculation by FEM coupled to circuit," in IEEE Transactions on Magnetics, vol. 53, no. 6, pp. 1-4, (2017). June Art no. 7401804

[19.] Arısoy A, Kalenderli Ö, Electrıc Field Analysıs Of Hvac Testing Unit Using Finite Element Method, journal of EMO (2000).

\section{How to Cite This Article}

Özüpak Y., Medium Frequency Electric Field Analysis of Power Transformers in High Voltage System, Brilliant Engineering, 3(2021), 1-5. https://doi.org/10.36937/ben.2021.003.001 